\title{
Study of the Biochemical Composition of Senegalese Mango Varieties Intended for Export and Local Consumation
}

\author{
Ibrahima Ba ${ }^{1}$, Mouhamadou Fofana ${ }^{1}$, Macoumba Diouf ${ }^{2}$, Moussoukhoye Diop ${ }^{1}$ \\ ${ }^{1}$ Natural Products Laboratory (LPN), Department of Chemistry, Faculty of Science and Technology, Sheikh Anta Diop University \\ of Dakar, Dakar, Senegal \\ ${ }^{2}$ Direction Horticulture Sénégal, Dakar, Senegal \\ Email: ^baibrahima705@gmail.com
}

How to cite this paper: Ba, I., Fofana, M., Diouf, M. and Diop, M. (2019) Study of the Biochemical Composition of Senegalese Mango Varieties Intended for Export and Local Consumation. Journal of Biosciences and Medicines, 7, 110-120.

https://doi.org/10.4236/jbm.2019.77009

Received: June 9, 2019

Accepted: July 19, 2019

Published: July 22, 2019

Copyright () 2019 by author(s) and Scientific Research Publishing Inc. This work is licensed under the Creative Commons Attribution International License (CC BY 4.0).

http://creativecommons.org/licenses/by/4.0/

\begin{abstract}
Biochemical characterization was carried out on five mango varieties grown in Senegal, two of which are intended for export (Kent and Keitt) and three to local consumption, on the one hand, and to national marketing, on the other. It can be seen that the flavanols composition is between " $0.74 \pm 0.03 \mathrm{mg} / 100$ g" to " $4.70 \pm 0.33 \mathrm{mg} / 100 \mathrm{~g}$ " and the total polyphenols composition is " 265.83 $\pm 33.70 \mathrm{mg}$ gallic acid/100 g" to " $834.29 \pm 25.78 \mathrm{mg}$ gallic acid/100 g". This analysis shows that the variety $\mathrm{Bk}$ is richer in polyphenols followed by the variety Dr then Knt and finally the lowest proportions are noted with the varieties Kt and SL. The analysis of antioxidant activity shows us percentages ranging from " $4.16 \% \pm 2.68 \%$ inhibition" to " $50.21 \% \pm 3.91 \%$ inhibition". It was noted that the SL and Knt varieties give the highest inhibition percentages of " $50.21 \pm 3.91$ " and " $33.97 \pm 0.36$ " respectively. Variety Bk gives the lowest percentage followed by variety Kt. The Dr variety is the richest in flavonoids " $11.75 \pm 0.27$ " followed by the SL variety " $11.27 \pm 0.10$ " and the lowest composition is noted in the Knt variety " $1.91 \pm 0.04$ ". For total sugars, the most important contents are found in the varieties: $\mathrm{Bk}$ " $12.71 \pm 0.32 \mathrm{mg} / 100$ g" followed by Dr " $11.5 \pm 0.33 \mathrm{mg} / 100 \mathrm{~g}$ " and SL " $9.86 \pm 0.06 \mathrm{mg} / 100 \mathrm{~g}$ ". This time the variety Kt stands out with also important proportions. For quantification, there is a slight difference in the values obtained for the different varieties studied. However, the highest values are observed in local varieties: “ $0.36 \pm 0.06 \mathrm{~g} / 100 \mathrm{~g}$ ” for Bk and Dr followed by SL “ $0.31 \pm 0.01 \mathrm{~g} / 100 \mathrm{~g}$ ”. The study of the mineral composition shows that the local varieties are the richest and the Knt variety is the poorest. The difference in composition noted within the same variety can be explained by the fact that some varieties have an advanced maturity compared to others.
\end{abstract}




\section{Keywords}

Biochemical Composition, Mango, Senegal, Export and Local Consumption

\section{Introduction}

Mango is one of the most accessible and consumed fruits in Senegal. With the development of export, many local varieties are replaced by those intended for export so some disappear completely. The objective of this work is the biochemical characterization of five mango varieties in Senegal, two of which are intended for export (Kent and Keitt) and three for local consumption (Sierra-leone, Diourrou and bouko diékhal). Currently in Senegal, an increase in the processing of local products, particularly mango, is noted thanks to the emergence of new eating habits. The work contributes on the one hand to giving processors a better orientation and on the other hand to preserving the best varieties of local mangoes. New eating habits mean that today, Senegalese mango is transformed into juice, nectars or dried ... Local varieties that are not intended for export are the most used in processing. Although Senegal is a mango producing country, studies on the biochemical characterization of cultivated varieties are almost non-existent. The objective of this theme is the biochemical characterization of Senegalese mango varieties for export and local consumption. To do this, we first measured total polyphenols, flavonoids and then flavonols and then focused on the antioxidant capacity of mango varieties, their mineral composition and the amount of protein they contain. These chemical families studied play an essential role in terms of diet and health. For example, phenolic compounds are found in foods of plant origin. Their antioxidant capacity would protect the body's cells from damage caused by free radicals. They would reduce the risk of the appearance of several diseases [1]. It is advisable to combine animal and vegetable proteins because, if the former makes it possible to cover the needs in essential amino acids, it is preferable to maintain a balanced ratio of essential amino acids to non-essential amino acids, apparently [2]. Trace elements are involved in the production of certain hormones and enzymes. They help to protect against certain toxic substances and regulate organic functions through a balancing action [3].

\section{Material and Methods}

\subsection{Material}

\subsubsection{Sample Origin}

The mango samples used in this work come from two areas of Senegal: Kaguitt village in the Ziguinchor region and Keur Mbir Ndao in the Thiès region.

In the southern zone, four mango varieties were harvested, two of which are for export and two varieties specific to this locality for national marketing, which are highly prized by consumers. In the Niayes area, a variety intended for na- 
tional marketing was collected.

\subsubsection{Sampling Techniques}

Each variety is harvested from three feet of mango trees at three levels per mango tree (upper level, middle level and lower level). The varieties for export collected in the southern zone are: Kent and Keitt, and the local varieties Diourou and Sierra-leone are collected in the southern zone and the Boukodiekhal variety in the Niayes zone (Photo 1).

\subsection{Physical and Chemical Analysis of the Different Samples}

\subsubsection{Determination of Total Polyphenols, Flavonoids, Flavonols and Antioxidant Activity}

For polyphenols, the Follin-Ciocalteu method is used, which consists of oxidizing the oxidizable groups of phenols in a basic medium. Blue colored reduction products have an absorption intensity proportional to the amount of polyphenols present. Absorptions are read at "760 nm". In reality, this is a calibration method using a gallic acid solution as the reference polyphenol. From this standard solution, daughter solutions with concentrations ranging from " 0.01 to 0.1 $\mathrm{g} / \mathrm{l}$ " are prepared. This will allow the $\mathrm{DO}=\mathrm{f}(\mathrm{C})$ curve to be plotted, otherwise says the linear (affine) response calibration curve. Thus, the results calculated from the average of three tests are expressed in g gallic acid equivalents per " 100 g", extract. To do this, "50 $\mu$ " of extract is determined using the Folin-Ciocalteu reagent according to the method developed [4]. The concentration of total polyphenols is given by the relationship:

$$
C_{P}=\frac{(A-b)}{a} * F_{d} * \frac{v}{1000} * \frac{100}{m}
$$

$C_{p}$ : Total polyphenol content expressed in "g gallic acid equivalent/100 g"; $A$ : Actual absorption of the sample; a: Guiding coefficient of the calibration line = "3.12"; $b$ : Ordinate at the origin of the calibration line $=$ " 0.0696 ";

$F_{d}$. Dilution factor;

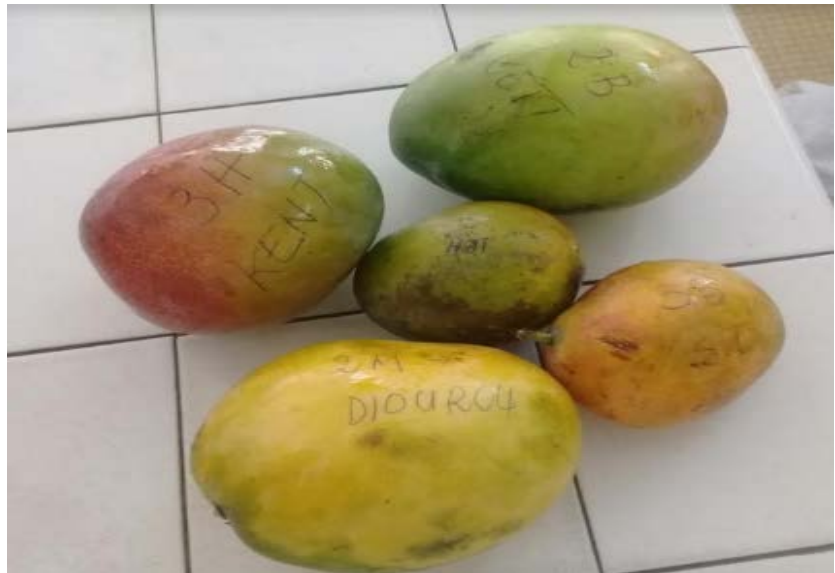

Photo 1 . Five mango varieties. 
v. Extraction volume " $\mathrm{mL}$ ";

$m$ : Test sample "g".

The flavonoid content of the extracts is determined using the colorimetric method described in [5]. The results are expressed in g catechin equivalent per $100 \mathrm{~g}$ of product according to the equation.

$$
C=\frac{A^{*} P_{m}}{\varepsilon} * f_{d} * \frac{v}{1000} * \frac{100}{m}
$$

$C$ : Total flavonoid content expressed in "g catechin equivalent/100 g";

$A$ : Absorbance of the sample;

$P_{m}$ : Catechin molecular weight $=$ " $290.26 \mathrm{~g} / \mathrm{mol} " ;$

$\varepsilon$. Molar extinction coefficient $=$ "10 $332 \mathrm{~L} / \mathrm{mol} \cdot \mathrm{cm}$ ";

$F_{d .}$ Dilution factor;

$v$. Extraction volume " $\mathrm{mL}$ ";

$m$ : Test sample " $\mathrm{g}$ ".

Antioxidant activity was assessed with 2,2-diphenyl-1-pycrilhydrazyl (DPPH) according to the method described [6]. In addition, some adjustments have been made to this protocol. The method is based on the ability of an extract to give a singulet electron to the free radical DPPH of dark violet coloring to stabilize it in $\mathrm{DPPH}$ of yellow-green coloring. This activity is compared to that of a control antioxidant (quercetin). Thus, " $2 \mathrm{~mL}$ " of $\mathrm{DPPH}$ " $0.1 \mathrm{mM}$ ” in alcohol was introduced into a test tube containing " $0.5 \mathrm{~mL}$ " of sample. The mixture was stirred for five [7] minutes, then incubated at dark and room temperature for "30 minutes". After this incubation period, the absorbance was read at "517 nm" against a blank " $0.5 \mathrm{~mL}$ " sample and " $2 \mathrm{~mL}$ " methanol using a UV spectrophotometer (SPECORD 200 PLUS). The antiradical activity is expressed as a percentage of reduced DPPH according to the equation ...

$$
A A R(\%)=\frac{\text { absorbancy }_{\text {control }}-\text { Absorbancy }_{\text {sample }}}{\text { Absorbancy }_{\text {control }}}
$$

Also, the baobab oil concentration reducing 50\% pH (IC50) is determined graphically on the antiradical activity (AAR) curve as a function of the oil concentration.

\subsubsection{Total and Reducing Sugar Conten}

For reducing sugars and total sugars, the Luff-Schoorl method is used after hydrolysis by $\mathrm{HCl}$ for " 3 minutes" of boiling. The sweet liquor is hot oxidized by a copper-alkaline solution and the excess copper liquor is titrated by iodometry. At the same time, the cuproalkaline solution liquor is titled. The total sugar content, expressed in $\mathrm{mg}$ per $100 \mathrm{~mL}$ of product, is given by the relationship:

$$
\% \text { reducing sugars }=m \times \frac{100}{25} \times d \times \frac{100}{V}
$$

$V$ : Test sample in millilitres (liquid sample);

$V_{0}$ : Volume of " $0.1 \mathrm{~N}$ " thiosulfate solution used to titrate the blank;

$V_{1}$ : Volume of " $0.1 \mathrm{~N}$ " thiosulfate solution used to titrate the sample; 
$m$ : mass of sugar, expressed in $\mathrm{mg}$, corresponding to the difference in volume between the blank and the sample $\left(V_{0}-V_{1}\right)$.

d: dilution factor.

\subsubsection{Protein Content and Mineral Composition}

\section{1) Protein content}

This European standard specifies a method for determining the nitrogen content of fruits and fruit juices using the Kjeldahl method, and a method for calculating the crude protein content. The method does not distinguish between protein nitrogen and non-protein nitrogen. For this purpose, "2 g" of pulp is mineralized with " $25 \mathrm{~mL}$ " of water, " $18 \mathrm{~mL}$ " $\mathrm{H}_{2} \mathrm{SO}_{4}$ and " $10 \mathrm{~g}$ " $\mathrm{K}_{2} \mathrm{SO}_{4}$ as a catalyst. The whole is digested at " $420^{\circ} \mathrm{C} \pm 10^{\circ} \mathrm{C}$ " for " 2 hours" until a clear solution is obtained; the solution is allowed to cool before being poured into a " $250 \mathrm{~mL}$ " flask which is then filled with distilled water. To quantify proteins, total nitrogen is measured. In order to achieve this, a vial is prepared " $50 \mathrm{~mL}$ " volumetric scoop, " $2 \mathrm{~mL}$ " double sodium potassium tartrate and " $2 \mathrm{~mL}$ " Nessler, the previously neutralised solution is added until a colour is obtained. Orange and finally we complete it with water.

\section{2) Mineral composition}

To determine the mineral composition of each variety, the protocol established [8]. For this purpose, " $2 \mathrm{~g}$ " of pulp is weighed and burned at " $550^{\circ} \mathrm{C}$ " for " 4 hours" and the capsules are recovered and cooled in a desiccator, then " 10 $\mathrm{mL}$ " of $\mathrm{HCl}$ " $6 \mathrm{M}$ " is added and evaporated before being filled into a " $100 \mathrm{~mL}$ " flask.

\section{Results and Discussions}

\subsection{Composition of Total Polyphenols and Flavonols}

Figure 1 shows the composition of total polyphenols "mg gallic acid/100 g" and flavonols "mg/100 g" of the five mango varieties from two areas of Senegal.

For polyphenols, the Follin-Ciocalteu method is used, which consists of oxidizing the oxidizable groups of phenols in a basic medium.

According to various studies, we have noted that phenolic compounds are found throughout the plant kingdom and that they are good antioxidants because they can easily give a hydrogen atom or an electron [9] which would reduce oxidative stress by forming stable radicals.

This study shows a flavonol composition between " $0.74 \pm 0.03 \mathrm{mg} / 100 \mathrm{~g}$ " to " $4.70 \pm 0.33 \mathrm{mg} / 100 \mathrm{~g}$ " and a total polyphenol composition of " $265.83 \pm 33.70$ mg gallic acid/100 g" to " $834.29 \pm 25.78 \mathrm{mg}$ gallic acid/100 g".

This analysis shows that the variety Bk is richer in polyphenols followed by the variety Dr then Knt and finally the lowest proportions are noted with the varieties Kt and SL. The consumption of mangoes could play an important protective role [10]. The total polyphenol composition of the varieties is higher than that found in the literature [11].

Since polyphenols have several sub-categories, the focus has been on flavonols. It 


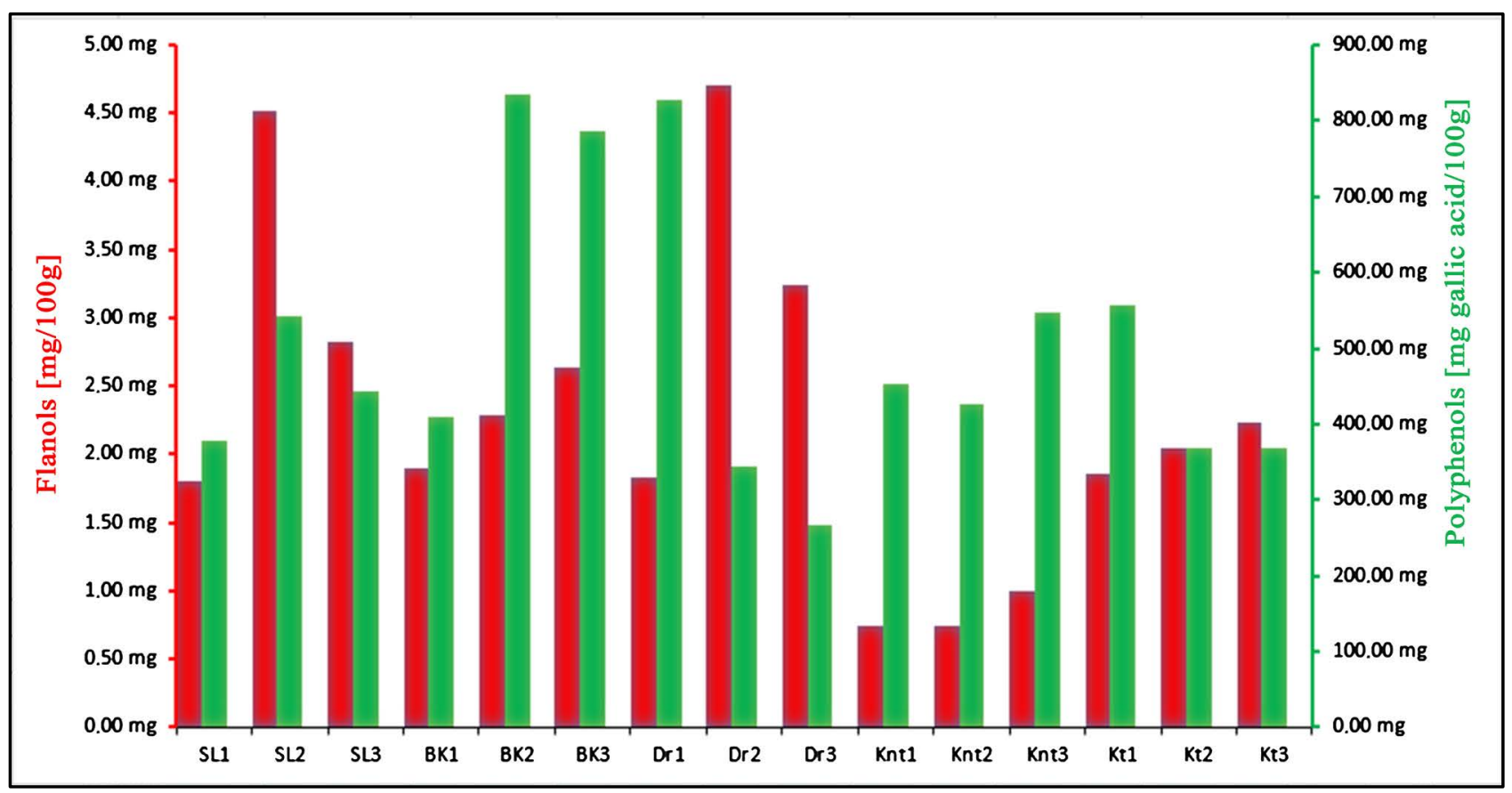

Abbreviations: SL siérra-leonne, Bk bouko diékhal, Dr diourrou, Knt kent and Kt keitt. 1 fruit picked from the upper part of the plant, 2 fruit picked from the middle part of the plant and 3 fruit picked from the lower part of the plant.

Figure 1. Polyphenols and flavonols composition of mango varieties.

has been reported that the consumption of flavonols would reduce the risk of developing cancer. For this reason, it could be the most popular variety interesting in the world.

This analysis reveals that the Dr variety has the best flavonol composition followed by the SL variety and then the Bk variety. The variety Knt has the lowest composition. Mango is characterized by the presence of high amounts of polyphenols whose antioxidant action protects the body's cells from damage caused by free radicals. They would reduce the appearance of several diseases, including cancers [12].

\subsection{Flavonoid Composition and Antioxidant Activity}

In Figure 2 we have represented the results of the analysis of the antioxidant activity "\% inhibition" and flavonoid composition "mg catechin/100 g" of the five mango varieties.

Antioxidant activity was evaluated with 2,2-diphenyl-1-pycrilhydrazyl (DPPH) according to the method described [7] and the flavonoid content of the extracts is determined using the colorimetric method described [6]. Since polyphenol richness is only a simple factor, the content into flavonoids. It was noted that the flavonoid composition reveals averages between " $1.86 \pm 0.02 \mathrm{mg}$ catechin/100 g" and "11.75 $\pm 0.27 \mathrm{mg}$ catechin/100 g". The Dr variety is the richest in flavonoids

"11.75 $\pm 0.27 \mathrm{mg}$ catechin/100 g" followed by the SL variety " $11.27 \pm 0.10 \mathrm{mg}$ catechin/100 g" and the lowest composition is noted in the Knt variety " $1.91 \pm$ $0.04 \mathrm{mg}$ catechin/100 g". 


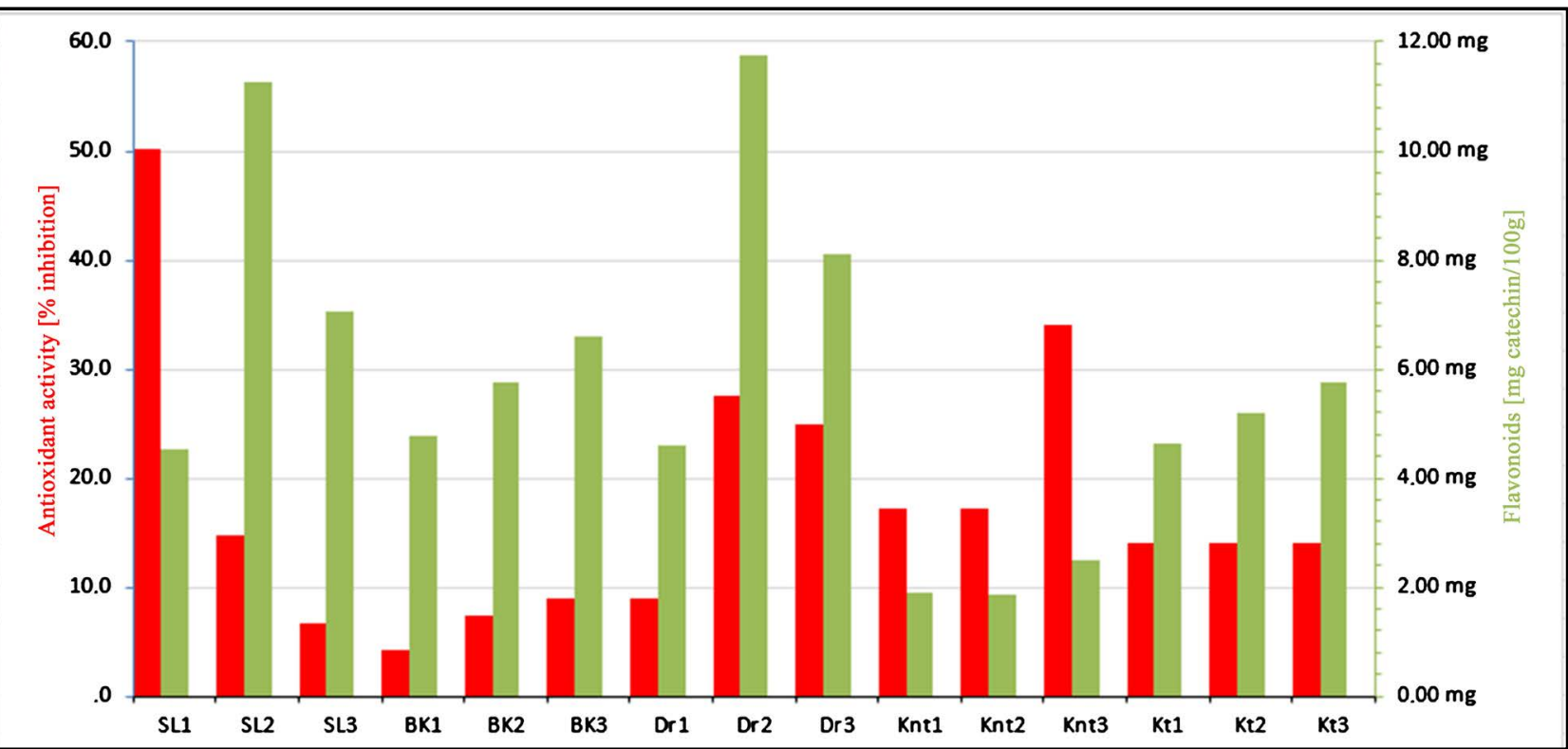

Abbreviations: SL siérra-leonne, Bk bouko diékhal, Dr diourrou, Knt kent and Kt keitt. 1 fruit picked from the upper part of the plant, 2 fruit picked from the middle part of the plant and 3 fruit picked from the lower part of the plant.

Figure 2. Flavonoid composition and antioxidant activity.

Oxidation is a reaction that transfers electrons from a substance to an oxidizing agent. It can produce free radicals that lead to chain reactions destructive. An example is the action of the radical $\mathrm{OH}$, which can react with molecules such as DNA, proteins, nucleotides, leading to necrosis. The antioxidants are molecules capable of stopping or slowing down these chain reactions by combining with free radicals, thus suppressing their action.

The analysis of antioxidant activity shows us percentages ranging from " $4.16 \%$ $\pm 2.68 \%$ inhibition" to " $50.21 \% \pm 3.91 \%$ inhibition". It was noted that the SL and Knt varieties give the highest inhibition percentages of " $50.21 \% \pm 3.91 \%$ inhibition" and " $33.97 \% \pm 0.36 \%$ inhibition" respectively. Variety Bk gives the lowest percentage followed by variety Kt.

\subsection{Total Sugar, Reducing Sugar and Protein Content}

The contents of total sugars, reducing sugars and the amount of protein are reported in the table.

For reducing sugars, it has been observed that the most important contents are found respectively in the varieties: SL " $3.83 \pm 0.07 \mathrm{mg} / 100 \mathrm{~g}$ ", Bk " $3.80 \pm 0.05$ $\mathrm{mg} / 100 \mathrm{~g}$ " and Dr "3.48 $\pm 0.21 \mathrm{mg} / 100 \mathrm{~g}$ ". Varieties Kt and Knt give the lowest proportions respectively " $2.33 \pm 0.07 \mathrm{mg} / 100 \mathrm{~g}$ " and " $2.18 \pm 0.06 \mathrm{mg} / 100 \mathrm{~g}$ ".

For total sugars, the most important contents are found in the varieties: $\mathrm{Bk}$ "12.71 $\pm 0.32 \mathrm{mg} / 100 \mathrm{~g}$ ” followed by $\mathrm{Dr}$ " $11.5 \pm 0.33 \mathrm{mg} / 100 \mathrm{~g}$ ” and SL “9.86 \pm 0.06 $\mathrm{mg} / 100 \mathrm{~g}$ ". This time the variety Kt stands out with also important proportions.

This study reveals that the varieties: SL, Dr. and Bk have significant total sugar contents that are above the average of the varieties found in the literature. These three varieties mentioned above are richer in reducing sugars. Variety Knt gives 
the lowest sugar composition which is below the average of the varieties found in the literature [13].

The Kjeldahl method was used to determine the amount of protein in the varieties. The quantification of the proteins of each of the varieties studied is reported in Table 1. For this quantification, there is a slight difference in the values obtained for the varieties studied. However, the highest values are observed in local varieties: " $0.36 \pm 0.06 \mathrm{~g} / 100 \mathrm{~g}$ " for Bk and Dr. followed by SL " $0.31 \pm$ $0.01 \mathrm{~g} / 100 \mathrm{~g}$ ”. Proteins have many functions: structural proteins (collagen), contractile proteins (myosin), transport proteins (albumin), immune proteins (immunoglobulins), enzymatic proteins, hormones, receptors, etc. The preparation of these mango varieties can play an important role in protein intake.

The protein contents of the varieties are slightly lower than those found in the literature [14].

\subsection{Mineral Composition}

The mineral composition was then examined. To do this, sodium, potassium, calcium and magnesium levels were measured. The results are reported in Table 2 and are expressed in " $\mathrm{mg} / 100 \mathrm{~g}$ ".

The adage is perfectly adapted to mineral salts and trace elements which are essential to life and health, yet necessary in minute quantities in the body $(4 ; 5)$.

The analysis of the composition shows disparate results for $\mathrm{Ca}^{2+}, \mathrm{K}^{+}$and $\mathrm{Na}^{+}$.

Table 1. Total sugar, reducing sugar and protein content.

\begin{tabular}{cccc}
\hline Varieties & Reducing sugars “mg/100 g” & Total sugars “ $\mathrm{mg} / 100 \mathrm{~g}$ ” & Proteins “g/100 g” \\
\hline SL1 & $3.63 \pm 0.21$ & $9.86 \pm 0.06$ & $0.24 \pm 0.01$ \\
SL2 & $3.83 \pm 0.07$ & $9.19 \pm 0.25$ & $0.31 \pm 0.01$ \\
SL3 & $2.98 \pm 0.01$ & $9.14 \pm 0.31$ & $0.27 \pm 0.06$ \\
BK1 & $3.70 \pm 0.39$ & $8.33 \pm 0.01$ & $0.36 \pm 0.06$ \\
BK2 & $3.11 \pm 0.06$ & $8.48 \pm 0.22$ & $0.20 \pm 0.06$ \\
BK3 & $3.80 \pm 0.05$ & $12.71 \pm 0.32$ & $0.20 \pm 0.06$ \\
Dr1 & $3.48 \pm 0.99$ & $9.87 \pm 0.44$ & $0.36 \pm 0.06$ \\
Dr2 & $3.33 \pm 0.07$ & $11.35 \pm 0.38$ & $0.24 \pm 0.01$ \\
Dr3 & $3.33 \pm 0.16$ & $8.58 \pm 0.31$ & $0.32 \pm 0.01$ \\
Knt1 & $2.18 \pm 0.01$ & $6.58 \pm 0.16$ & $0.24 \pm 0.06$ \\
Knt2 & $1.82 \pm 0.13$ & $2.75 \pm 0.14$ & $0.28 \pm 0.01$ \\
Knt3 & $1.72 \pm 0.40$ & $3.25 \pm 0.38$ & $0.20 \pm 0.06$ \\
Kt1 & $2.18 \pm 0.06$ & $9.52 \pm 0.2$ & $0.20 \pm 0.06$ \\
Kt2 & $2.33 \pm 0.07$ & $9.56 \pm 0.28$ & $0.28 \pm 0.06$ \\
Kt3 & $2.20 \pm 0.39$ & $9.54 \pm 0.24$ & $0.28 \pm 0.06$ \\
\hline
\end{tabular}

Abbreviations: SL siérra-leonne, Bk bouko diékhal, Dr diourrou, Knt kent and Kt keitt. 1 fruit picked from the upper part of the plant, 2 fruit picked from the middle part of the plant and 3 fruit picked from the lower part of the plant. 
Table 2. Mineral composition.

\begin{tabular}{ccccc}
\hline Varieties & $\mathrm{Ca}^{2+}$ "mg/100 g" & $\mathrm{Mg}^{2+}$ “mg/100 g" & $\mathrm{K}^{+}$“mg/100 g" & $\mathrm{Na}^{+}$“mg/100 g" \\
\hline SL1 & $18.39 \pm 0.33$ & $2.55 \pm 0.42$ & $21.12 \pm 0.03$ & $10.02 \pm 0.02$ \\
SL2 & $21.71 \pm 0.32$ & $1.15 \pm 0.25$ & $1.11 \pm 0.03$ & $0.47 \pm 0.04$ \\
SL3 & $37.81 \pm 0.43$ & $2.90 \pm 0.42$ & $7.87 \pm 0.03$ & $7.58 \pm 0.03$ \\
BK1 & $23.56 \pm 0.33$ & $3.9 \pm 0.42$ & $24 \pm 0.03$ & $10.05 \pm 0.03$ \\
BK2 & $14.08 \pm 0.33$ & $3.25 \pm 0.22$ & $20.56 \pm 0.03$ & $5.9 \pm 0.02$ \\
BK3 & $26.96 \pm 0.41$ & $5.53 \pm 0.23$ & $19.43 \pm 0.03$ & $9.63 \pm 0.01$ \\
Dr1 & $42.36 \pm 0.32$ & $4.67 \pm 0.23$ & $20.19 \pm 0.02$ & $15.12 \pm 0.03$ \\
Dr2 & $24.75 \pm 0.41$ & $2.92 \pm 0.25$ & $16.56 \pm 0.02$ & $18.15 \pm 0.03$ \\
Dr3 & $30.70 \pm 0.41$ & $4.66 \pm 0.22$ & $18.76 \pm 0.01$ & $10.99 \pm 0.03$ \\
Knt1 & $6.16 \pm 0.31$ & $0.65 \pm 0.23$ & $4.22 \pm 0.02$ & $1.49 \pm 0.03$ \\
Knt2 & $4.32 \pm 0.31$ & $0.69 \pm 0.22$ & $5.13 \pm 0.01$ & $1.64 \pm 0.03$ \\
Knt3 & $1.00 \pm 0.40$ & $0.36 \pm 0.25$ & $0.54 \pm 0.02$ & $0.38 \pm 0.03$ \\
Kt1 & $15.35 \pm 0.33$ & $1.56 \pm 0.22$ & $13.29 \pm 0.01$ & $5.26 \pm 0.03$ \\
Kt2 & $39.34 \pm 0.32$ & $2.19 \pm 0.24$ & $26.16 \pm 0.02$ & $14.29 \pm 0.03$ \\
Kt3 & $6.33 \pm 40$ & $1.15 \pm 0.22$ & $10.49 \pm 0.02$ & $2.08 \pm 0.03$ \\
\hline
\end{tabular}

Abbreviations: SL siérra-leonne, Bk bouko diékhal, Dr diourrou, Knt kent and Kt keitt. 1 fruit picked from the upper part of the plant, 2 fruit picked from the middle part of the plant and 3 fruit picked from the lower part of the plant.

For the $\mathrm{Ca}^{2+}$ composition, we can see that the $\mathrm{Dr} 1$ variety is the richest " 42.36 $\pm 0.32 \mathrm{mg} / 100 \mathrm{~g}$ ” followed by Kt2 " $39.34 \pm 0.32 \mathrm{mg} / 100 \mathrm{~g}$ ” and then SL3 “37.81 \pm $0.31 \mathrm{mg} / 100 \mathrm{~g}$ ". Variety Knt is the poorest variety in $\mathrm{Ca}^{2+}$ with amounts between "6.16 $\pm 0.32 \mathrm{mg} / 100 \mathrm{~g}$ " and " $1.00 \pm 0.40 \mathrm{mg} / 100 \mathrm{~g}$ ".

For the composition in $\mathrm{Mg}^{2+}$ the results are quite homogeneous. $\mathrm{Bk} 3$ is the richest in $\mathrm{Mg}^{2+}$ " $5.53 \pm 0.23 \mathrm{mg} / 100 \mathrm{~g}$ " followed by $\operatorname{Dr} 1$ " $4.60 \pm 0.23 \mathrm{mg} / 100 \mathrm{~g}$ " and then the SL3 variety " $2.90 \pm 0.42 \mathrm{mg} / 100 \mathrm{~g}$ ". The Knt variety remains the poorest in $\mathrm{Mg}^{2+}$. For the amount of $\mathrm{K}^{+}$, variety $\mathrm{Kt} 2$ is the richest " $26.16 \pm 0.02$ $\mathrm{mg} / 100 \mathrm{~g}$ " followed respectively by SL1 " $21.12 \pm 0.03 \mathrm{mg} / 100 \mathrm{~g}$ ” and Dr1 "20.19 $\pm 0.02 \mathrm{mg} / 100 \mathrm{~g}$ ". For this quantity in $\mathrm{K}^{+}$the variety $\mathrm{Knt}$ is also the poorest. For the analysis of the $\mathrm{Na}^{+}$composition, it can be seen that the variety $\mathrm{Dr} 2$ has the highest amount " $18.15 \pm 0.03 \mathrm{mg} / 100 \mathrm{~g}$ " followed by Kt2 " $14.29 \pm 0.03 \mathrm{mg} / 100$ g" then the varieties SL1 and Bk1 "10.05 $\pm 0.03 \mathrm{mg} / 100 \mathrm{~g}$ ". The Knt variety is also the poorest in $\mathrm{Na}^{+}$. The study of the mineral composition shows that the local varieties are the richest and the Knt variety is the poorest. The difference in composition noted within the same variety can be explained by the fact that some varieties have an advanced maturity compared to others.

\section{Conclusion}

The study of the biochemical characterization of these mango varieties has made it possible to identify local varieties of nutritional interest. For the polyphenol 
composition, the two varieties SL and $\mathrm{Bk}$ are the richest. Compared to antioxidant activity, the local variety SL gives the highest percentage of inhibition. Local varieties also give the best results in mineral composition and protein quantification. These varieties, mainly intended for local consumption, were less taken into account in the production chain. With the development of mango exports, several of these varieties have disappeared in many Senegalese orchards to the detriment of Kent and Keitt. This analysis shows the need to carry out studies to enhance the value of these varieties, such as processing capacity, but also to reserve a place for them in the international marketing circuit. This characterization also provides guidance to consumers. Dr mango consumption can help fight against aging and cancer because it is very rich in polyphenols. The Dr variety has given important values for all the parameters studied so its flattening is essential on the one hand and it is also interesting to conduct its study in the field of food health on the other hand. The two remaining local varieties have also revealed important values but they are a little more fibrous than the Dr variety which does not contain any.

\section{Conflicts of Interest}

The authors declare no conflicts of interest regarding the publication of this paper.

\section{References}

[1] Willcox, J., Ash, S. and Catignani, G. (2004) Antioxidants and Prevention of Chronic Disease. Critical Reviews in Food Science and Nutrition, 44, 275-295. https://doi.org/10.1080/10408690490468489

[2] Apports Nutritionnels Conseillés (ANC) (2007) Rapport de l'AFSSA Protéines. https://www.anses.fr/Documents/NUT-Ra-Proteines

[3] Hahm, T.-S., Park, S.-J. and Lo, Y.M. (2009) Effects of Germination on Chemical Composition and Functional Properties of Sesame (Sesamum indicum L.) Seeds. Bioresource Technology, 100, 1643-1647.

[4] Martin-Yken, H., Dagkessamanskaia, A., De Groot, P., Ram, A., Klis, F. and François, J. (2001) Saccharomyces cerevisiae YCRO17clCWH43 Encodes a Putative Sensor/Transporter Protein Upstream of the $B C K 2$ Branch of the PKC1-Dependent Cell Wall Integrity Pathway. Yeast, 18, 827-840. https://doi.org/10.1002/yea.731

[5] Kim, J.H., Woo, D.S., Lee, S.K., Lee, Y.L., Park, C.H., Ryu, H.W. and Lee, J.H. (2014) Comparative Assessment of Compositional Components, Antioxidant Effects, and Lignan Extractions from Korean White and Black Sesame (Sesamum indicum L.) Seeds for Different Crop Years. Journal of Functional Foods, 7, 495-505.

[6] Banji, A., Adebayo, O. and Oluwatosin, S. (2016) Physiochemical Properties and Antioxidant Potential of Persea Americana Seed Oil. Chemistry International, 2, 168-175.

[7] Mohamed, E., Souhail, B., Olivier, R., Christophe, B. and Hamadi, A. (2007) Quality Characteristics of Sesame Seeds and by-Products. Food Chemistry, 103, 641-650.

[8] Romani, A., Ieri, F., Turchetti, B., Mulinacci, N., Vincieri, F. and Buzzini, P. (2006) Analysis of Condensed and Hydrolysable Tannins from Commercial Plant Extracts. 
Journal of Pharmaceutical and Biomedical Analysis, 41, 15-20.

[9] Mohdaly, A.A.A., Smetanska, I., Ramadan, M.F., Mo-Hamed, A. and Mahmoud, S.A. (2011) Antioxidant Potential of Sesame (Sesamum indicum) Cake Extract in Stabilization of Sunflower and Soybean Oils. Industrial Crop and Products, 34, 952-959. https://doi.org/10.1016/j.indcrop.2011.02.018

[10] Manach, C., Williamson, G., Morand, C., Scalbert, A., Rémésy, C. and Clin, N. (2005) Bioavailability and Bioefficacy of Polyphenols in Humans. I. Review of 97 Bioavailability Studies. Nutrients, 81, 230-242.

[11] Soong, Y. and Barlow, P. (2006) Quantifcation of Gallic Acid and Ellagic Acid from Longan (Dimocarpus longan Lour.) Seed and Mango (Mangifera indica L.) Kernel and Their Effects on Antioxidant Activity. Food Chemistry, 97, 524-530.

https://doi.org/10.1016/j.foodchem.2005.05.033

[12] http://biocontact.over-blog.com

[13] Pierson, J., Monteith, G., Roberts-Thomson, S., Dietzgen, R., Gidley, M. and Shaw, P. (2014) Phytochemical Extraction, Characterisation and Comparative Distribution across Four Mango (Mangifera indica L.) Fruit Varieties. Food Chemistry, 149, 53-63. https://doi.org/10.1016/j.foodchem.2013.10.108

[14] Base de données des nutriments pour référence normative (2001) Département de l'Agriculture des Etats-Unis USDA. 